Article

\title{
Bounded Rationality in the Developmental Trajectory of Environmental Target Policy in China, 1972-2016
}

Rui Mu

Faculty of Humanities and Social Sciences, Dalian University of Technology, Linggong Road 2, Ganjingzi District, Dalian 116024, China; ruimu@dlut.edu.cn; Tel.: +86-139-0411-9150

Received: 1 December 2017; Accepted: 15 January 2018; Published: 15 January 2018

\begin{abstract}
This article applies the theoretical notion of "bounded rationality" to understand and to explain the updates of the Environmental Target Policy (ETP) in China during 1972-2016. An analytical framework is built up by combining the phase model and the stream model in policy science in order to trace the longitudinal transformation of the ETP. In addition, the article adopts the "event sequence method" to discover the dynamics of the problem, politics, and policy streams of the target policy and to identify the evolving coupling between the different streams. It shows that China's ETP has experienced five phases of development. For each phase the central government had its specific bounded rationality to make the crucial decision on the ETP. The decisions on the ETP in different phases were made when policy windows were open with the coupling of the problem, politics, and policy streams. As for the updates of the ETP, we find that the rationalities of the central governments in the five phases were limited by the emergent practices during the ETP implementation, which gave momentum to the central government to seek new solutions and to revise and adapt the ETP.
\end{abstract}

Keywords: environmental target; bounded rationality; multiple streams; longitudinal study; China

\section{Introduction}

After the founding of the People's Republic in 1949, the Chinese government adopted the "production comes first and living comes later" ideology, in order to recover the country from World War II through the promotion of rapid industrialization. This arrangement worked well for the construction and expansion of large state-owned industrial enterprises. However, after decades of industrial production in the absence of environmental regulations, catastrophic water pollution events occurred, signaling that China's ecological and environmental systems could no longer carry such large-scale, uncontrolled pollution. Confronted with the environmental pressure, the Chinese government introduced the environmental target policy (ETP) in 1989, stipulating that local governments should start to formulate annual environmental targets and issue emission permits based on these targets.

However, in late 2016 it became clear to the author of this article during interviews with public officials from the Government Performance Management Office in Beijing that the ETP has experienced several updates in the past three decades, partly due to harmful forms of strategic behavior on the part of local governments, as well as malpractices seen among a number of local officials in their interactions with the enterprises that illegally discharge excessive pollutants. Additionally, the shift of political attention in the center and the evolution of environmental policies and legislations in China also constituted the updates of the ETP. The first update occurred in 2001, when the targets were peeled off from local municipalities and banded with local cadres and their promotion. The second update happened in 2010. The ETP was updated from cadre evaluation (i.e., the assessment of local cadres in terms of their achievements of targets) to economic performance; the assessment on local economic performance has to incorporate the achievement of their environmental targets. In 2013, the third 
update of ETP was that it was linked to budgeting incentives. The regions of good environmental target records will obtain central fiscal transfer payment. The most recent update (the fourth one) took place around 2016, when the central government attached environmental targets directly to the large industrial enterprises by introducing a combination of market-based and financial incentives.

This developmental trajectory of the ETP in China poses the question of how the decisions on ETP in different phases were made and how to explain the updates of the ETP in China? To explore this puzzle, in Section 2, we first adopt the concept of "bounded rationality" from Herbert Simon [1] and applied this concept into the Chinese policy context of decentralized authoritarianism. By doing so, the article clarifies the bounded rationality of the Chinese central government in making environmental policies and in implementing these policies in local areas (provinces, municipalities and townships, etc.) in China. In Section 3, an analytical framework is built up by combining the "phase" model and the "stream" model. These two models are generally accepted and respected. The phase model is the most common approach both in science [2,3] and in policy practice [4], Policy development is represented in terms of a number of distinctive phases [5], with specific characteristics and participants in each phase. The stream model depicts policy-making as a combination of three separate concurrent streams (problems, politics, and policies) [6]. The streams have their own rules and they exist side-by-side. A policy decision emerges at the time point of coincidence of the three streams. The framework provides fundamental explanatory concepts for analyzing and understanding the development of the ETP. In Section 4, the article reports its methods and sources of materials. In Section 5, the article presents the updates of ETP in five different developmental phases in China, with a time span of 1972-2016. In Section 6, the empirical evidence from Section 5 is systematically analyzed by the framework in Section 3. Finally, in Section 7, conclusions are drawn with regards to the research questions.

\section{Bounded Rationality in the Decentralized Authoritarian China}

Bounded rationality is a school of thought about decision making that developed from dissatisfaction with the "comprehensively rational" economic and decision theory models of choice [1]. Those models assume that preferences are defined over outcomes, that those outcomes are known and fixed, and that decision-makers maximize their net benefits by choosing the alternative that yields the highest level of utility. Like comprehensive rationality, bounded rationality assumes that actors are goal oriented, but bounded rationality takes into account the cognitive limitations of decision-makers in attempting to achieve those goals. Decision-makers' rationality is also limited by the tractability of the decision problem, the time available to make the decision, and the information available for problem diagnosis and policy/solution analysis [7]. Decision-makers, in the view of bounded rationality, act as satisficers, seeking a satisfactory solution rather than an optimal one. A major implication of bounded rationality for policy studies is that policy-makers have to face uncertainties involved in the processes of policy-making and policy implementation, and that they need to adapt prior policies, after experiencing the uncertainties and becoming learned, by employing more mental resources and thinking more systematically [8].

In order to explore how the rationality of the Chinese central government is bounded in environmental policy-making, we have to present the Chinese policy context that is featured by decentralized authoritarianism, the term first proposed by Landry [9] and developed by Zhu and Zhang [10]. In this article, we reconceptualize the policy context of decentralized authoritarianism that affects local policy implementation in China as a combination of fiscal semi-decentralization, administrative semi-authoritarian, and political personnel system. The first basic characteristic that shapes local policy implementation is fiscal semi-decentralization. The central and local governments have a shared financial distribution structure since the 1994 tax-sharing system, in which the central government obtains the large part of the tax resources and reallocates fiscal transfer payments to balance regional economic variations among local governments. As for environmental protection, the central government obtains the large part of the penalties that are collected by the local governments on polluting enterprises. Conversely, local governments are responsible for most of the expenditures 
on environmental governance. Consequently, facing the economic benefits brought by the polluting enterprises and the costs associated with environmental protection, the local governments have significant incentives to display strategic behaviors that harm the implementation of ETP.

The second characteristic that affects the implementation of ETP is administrative semi-authoritarianism. With respect to public affairs, although the administrative system dictates local governments to follow commands and policies from the central or superior governments, the local governments have a certain degree of discretion and autonomy in implementing the central policies. In the case of environmental protection, although the Chinese central government frequently promotes local environmental protection through national policy instruments and guidelines, such national polices are not coercive. Consequently, there may be significant variations in local areas in terms of willingness to formulate environmental policy measures in accordance with central intention.

Finally, a distinctive political personnel system controlled by the central government further complicates environmental protection in China, Local Chinese officials are not elected by voters in constituencies, but are uniformly selected and appointed by the superior government departments and superior leaders of the Communist Party of China (CPC). This selection process typifies a cadre personnel system, which is similar to the nomenklatura system of the Soviet Union. Local officials with greater ambition and more opportunities to advance in their careers are motivated to adopt central policies to show working abilities and party loyalty. However, for those who have little ambition or few opportunities to get promoted, policy compliance may be low, with shrinking efforts in policy implementation.

Under the decentralized authoritarian China, the central government will not know how the local governments will respond to the central environmental policies, given that a large part of revenues obtained from environmental inspections and penalties will be submitted to the central government. The central government will not know the degrees of willingness of the local governments to implement the central policies, and how different they are. The central government will not know to what extent an individual official is ambitious in career development and devotes energies in policy implementation. These "unknowns" are all uncertainties for the central government to implement the ETP locally. These uncertainties that the central government has to face account for the fact that the rationality of the central government is bounded and, thus, updates of policies become necessary and unavoidable.

\section{An Analytical Framework for Updates of ETP}

Section 2 provides the reasons for the Chinese central government to be boundedly rational and in the course of ETP implementation the central government faces uncertainties of local behavior, and have to learn from experienced uncertainties in order to think more systematically on policy adaptation. In light of this thought, this section builds up an analytical framework that can be used to explain and understand the empirical evidence on ETP implementation and updates.

The analytical framework is combined by two models, one the "phase" model and the other the "stream" model (Figure 1). As pointed out by Sato [11]: "[In many policy development analyses] policy can be understood and examined as a combination of several phases, which are interrelated but can still be conceived as distinct components that are determinants of government actions". The phase model takes the assumption of bounded rationality of government and depicts that policy making is the succession of different situations in the evolution of a policy. Koppenjan and Klijn [12] provide some indications on phase demarcation. They point out that each phase ends with a crucial decision, a decision that offers a solution for the problem that is central in a particular time period. That means a crucial decision heralds a new phase, where it guides the subsequent policy-making. If a phase results in a clear outcome and offers perspectives about what needs to be done, this will have a motivating and centripetal impact upon the actors involved in policy making. The actors for the next phase join when they see new chances, and thus a new phase emerges with new stakes, new perceptions, and new strategies. 


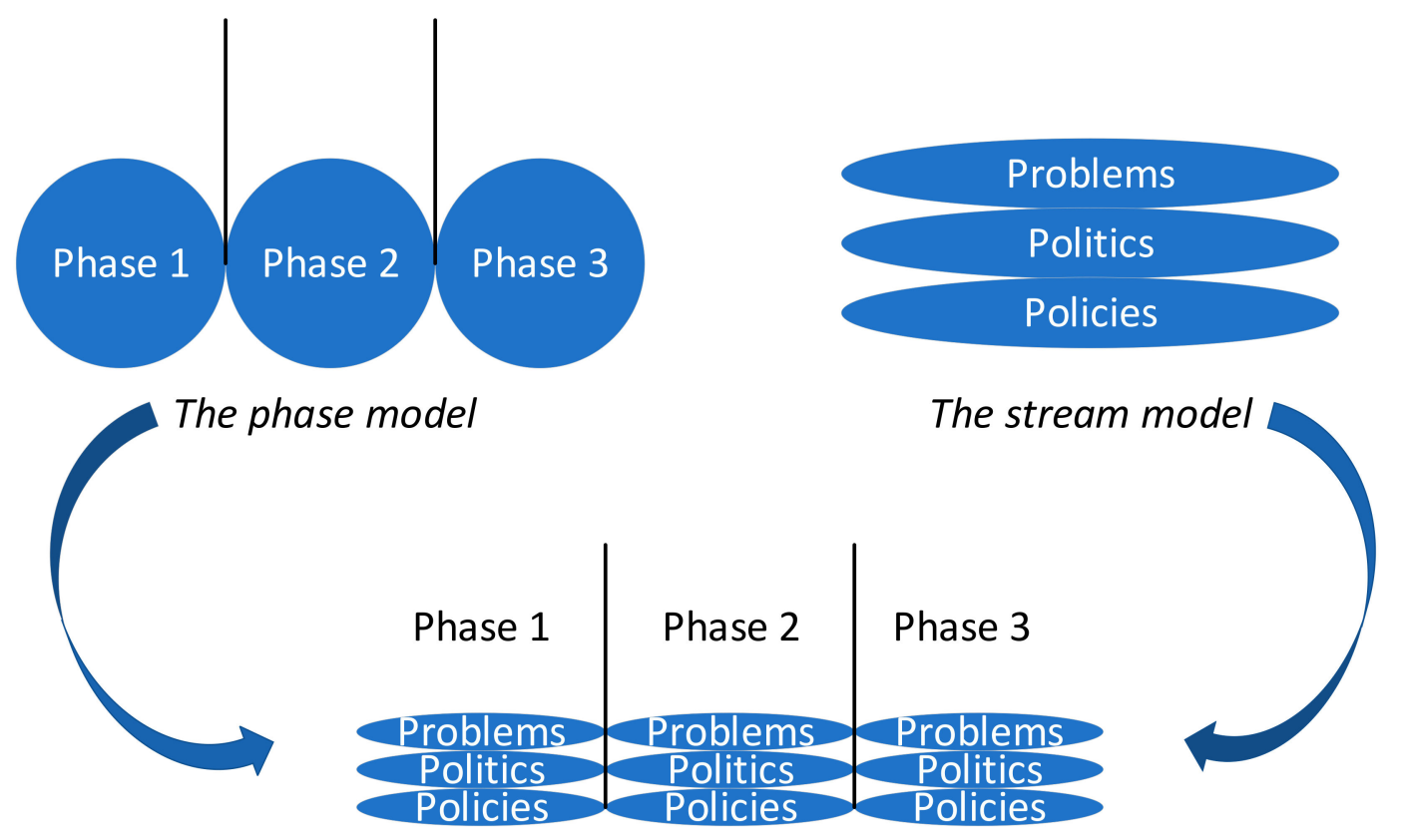

The combined model

Figure 1. An analytical framework combined with the "phase" model and the "stream" model.

The phase model, which divides policy-making activities horizontally, provides us a view that policy development is assumed to consist of different policy making phases, largely due to policy-makers' bounded rationality when making decisions. Each phase can be regarded as an update of the previous one after the policy makers experienced and learned from the previous phase. However, the phase model does not provide insights for us regarding what happens in each phase, how a certain situation becomes the problem on government agenda, and why a policy is selected for problems solution. For this reason, we combine the phase mode with the stream model by Kingdon [6] that divides activities of policy-making in the vertical dimension (Figure 1).

In Kingdon's influential book, Agendas, Alternatives, and Public Polices, a Multiple Streams Approach (MSA) is proposed to explain public policy agenda-setting and formulation: what determines the emergence of some ideas over others? Why are certain ideas chosen by governments to formulate public policies? Kingdon built up the MSA's conceptual framework by distinguishing three major components in public policy studies: problems, politics, and policies [6]. The three components are compared to "streams" flowing through the decision system, for the reason that they operate independently from one another with their own dynamics and rules, like streams bounded by their banks.

The problem stream focuses on the way policy makers learn about conditions and the way these conditions are defined as problems. Three methods are available for defining the conditions. One is indicators, which can be used to assess the existence and magnitude of a condition that, in turn, catches official attention. Second is dramatic events or crises that occasionally call attention to a condition. Third, feedbacks from existing programs can also bring conditions to the fore. However, not all conditions become problems. As Kingdon [6] asserts, problems are perceptual; conditions become problems when they are consistent with policy-makers' values and interests.

The political stream consists mainly of administrative and legislative turnover, public opinion or the "national mood" on an issue, and changes in government, such as a new administration or key personnel adjustments. Moreover, the advent of a new president or new secretary of state will signify potential ideological changes on public problems, and thus certain issues may receive more attention than others. 
The policy stream includes a wide variety of solutions floating around in the "policy primeval soap". These solutions may be generated by the experts from bureaucratic institutions, academic institutions and think tanks who share a common concern and constitute a policy community. For a solution to be considered seriously by policy-makers, it needs to be designed sufficiently feasible, cost effective, and acceptable to the general public. By doing so, the solution can survive the initial process of policy choice. Otherwise, it may either be combined with other solutions to form into new proposals, or just disappear.

By combining the phase model and the stream model, we can integrate the concept of "a crucial decision" and the concept of "coupling/decoupling of streams". An important feature of MSA is coupling. At critical moments, the streams are joined together and create fleeting opportunities for certain issues listed onto the government agenda and for advocates of proposals to push their pet solutions. Kingdon labels these moments policy windows [6]. In line with the MSA, we can understand the critical decision in the phase model as the policy solution generated from the policy window. Two conditions for policy windows can be distinguished: political attention paid to the problem; and a good fit between the recognized problem and the proposed policy solution. As the "combined" model shows in Figure 1, a crucial decision is made in phase 1 when the problem, politics, and policy streams converge and create a policy window. This crucial decision heralds a new phase, during which actors see opportunities and participate with varying interests and strategies. The new blood will decouple the three streams. That being said, problems change, or the solution for the old problem arouses new problems, political attention shifts, and policy solutions also evolve. The new streams in the next phase will converge again when the conditions for a policy window are present.

In this article, we adopt the combined model to depict the developmental trajectory of the ETP in China across 1972-2016. We use the concepts in the MSA and in the phase model as metaphors to describe the change of environmental problems, the shift of political attention, and the evolution of environmental policies in China. We do not examine the applicability of the MSA in the Chinese context. In the next section, we present our data sources and the way that we operationalize the combined model.

\section{Methods and Materials}

The methods that we apply to answer the research questions are inspired by longitudinal research approaches developed in sociology [13,14] and organizational research [15], and can be understood as a type of longitudinal case study. The central defining characteristic of our approach is that sequences of events serve as the basis for our analysis. Data are collected and recorded in event sequence datasets in which events are listed in chronological order, represented by a qualitative description of what happened in the past. In our research, events refer to both natural events and human actions and interactions that actors engage in environmental target policy. According to the concepts of the problem, politics, and policy streams in the MSA, we distinguish three major types of events in this research:

- Problem events: include natural events such as crises and catastrophes, focusing events of the media and the general public, and artificially constructed events, such as designing indicators and releasing indicator performance.

- Political events: include a meeting (sometimes several) in which political actors discuss problems and the possible solutions for them, and which produced political signals for policy preferences and reform directions, a decision on organizational (re)arrangement, a regulation that concerns cadre management and evaluation.

- Policy events: include legislative and policy actions, such as the establishment, adaptation or termination of legal prescriptions, including laws, regulations, policies, plans, directives, and formal procedures. 
Our approach of operationalizing the events according to the combined model is shown in Figure 2. The events are used to analyze the dynamics of the different streams. The problem events show the change of environmental conditions in China. The political events display the shift of political attention of China's top leaders on environmental conditions and the transformation of environmental problem definition. The policy events show the developments of China's environmental policy instruments and solutions for target achievement. We plot these events along the horizontal arrows according to the events' chronological sequence. We may merge some similar events and only plot the key or the representative events. We judge the coupling moments of the three streams in the way that during a period one or more political events identified certain problems and pay political attention to these problems by sending out explicit signals for policy proposals. Simultaneously, in the policy stream, there were policy events, either in place in prior to the political event or newly designed after that, that had the objectives to solve the same problem and, thus, confluence with the politics stream. Therefore, our main analytical method is to examine the contents of each event and determine the interactions between the events across different streams.

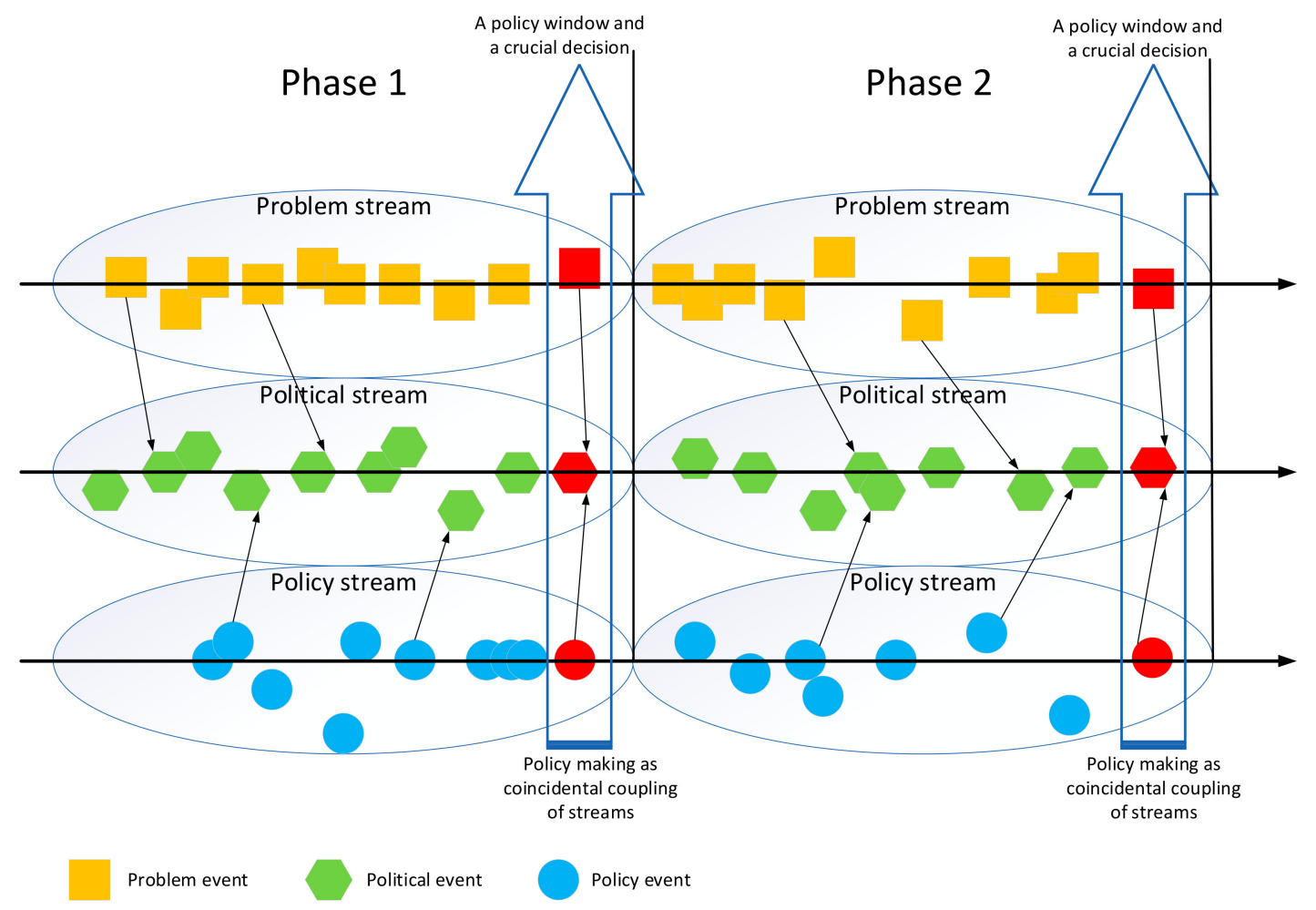

Figure 2. The operationalization of events in the combined model (source: adapted from Teisman, 2000, [4]).

The period we analyze in this research spans from 1972 to 2016, almost a half century. The data collection process started in March 2017 and ended in July 2017. Three researchers were collecting the event data at the same time, and then synthesized the data to cross-check any missing events in individual collection. Our sources of data include web pages, media reports, academic papers, and various types of documents produced by the multiple actors involved in the environmental protection in China. The main webpages we searched include open information platforms of each involved governmental organizations. In addition, we used Baidu (www.baidu.com) as the main search engine to find webpages outside the governmental organizations. For media reports and academic papers, we used CNKI.net to collect event data. CNKI (China National Knowledge Infrastructure) contains information generated from scientific research, newspapers, conferences, and statistical yearbooks. For the government documents, we went to the electronic resource platforms of the nation's archives for the past decisions made as to environmental management. To create the event 
sequence dataset, we read through all the collected documents, web pages and news items, and when relevant information was found, we manually entered this information in the event sequence dataset by writing an event description. Descriptions were later grouped together if they could be understood to refer to the same event. Typically, descriptions that are grouped together concern multiple observations (from different sources) of the same event. Finally, we collected 81 problem events, 28 political events, and 222 policy events. A list of the events can be found in the Supplementary Materials of this article.

\section{The Developmental Trajectory of ETP in China}

In this section, we distinguish the five phases of the ETP in China. Each phase represents a new update on the target policy. We use the event datasets to describe the three streams and highlight the critical events driving the coupling of the multiple streams to produce the windows of opportunity for the crucial decisions.

\subsection{Phase 1: Environmental Targets Banded with Local Municipalities, 1972-1989}

Problem stream. China's environmental target emerged from a water pollution crisis of Guanting reservoir, which is located in the Beijing suburb and is the major drinking water source for Beijing residents. In early spring of 1972, many dead fish appeared in this reservoir area, and the nearby residents were suffering from unexplained physical discomfort. Although this pollution event was not publicly reported, it still attracted the attention from the general public, and the leaders of the central government were greatly shocked due to this rather serious matter. The central government organized a broad scope investigation, and it was discovered that the water of Guanting reservoir had been heavily polluted by waste water from upstream factories [16]. This event made the central leaders in China realize that Guanting reservoir pollution was the epitome of the environmental condition of the 1970s' China where the ideology of "production comes first and living comes later" was prevailing across the country. A substantial number of industrial factories were constructed without installation of pollution treatment equipment [17].

Politics stream. The Guangting incident sounded the alarm for environmental protection in China. In August 1973, the central government convened the 1st National Environmental Protection Conference (NEPC), which produced the Provisions on Environmental Protection and Improvement. The Provisions stipulated that all construction projects must draw up environmental impact assessment (EIA) reports and install pollution treatment equipment before operation. To enforce the Provisions, the central government established the Environmental Protection Leading Group (EPLG) taskforce in 1974. The EPLG was formally institutionalized as the Environmental Protection Administration (EPA) under the Ministry of Housing and Urban-Rural Development (MHURD) after the Third Plenary Session of the 11th CPC Central Committee in 1982, and was administratively upgraded to an independent State Environmental Protection Administration (SEPA) after the 2nd NEPC in 1984. The establishment of the environmental authority and the upgrade of the EPA's bureaucratic status step-by-step were gradual movements within the politics stream that sent out a clear signal of China's determination for environmental protection. Later in 1989, at the 3rd NEPC, the participating ministries clearly perceived the strong political commitment to environmental protection, and jointly proposed the Environmental Targets Responsibility System, claiming that local municipalities should be responsible for formulating and monitoring annual environmental targets.

Policy stream. The policy stream during this phase focused on enacting environmental laws and establishing standards from scratch. In 1977, the Constitution of China was amended by writing: "the State protects the environment and natural resources against pollution and other damage". This adjustment provided a great momentum to the births of China's Environmental Protection Law (trial) (EPL) in 1979, the Marine Environmental Protection Law (MEPL) in 1983, the Water Pollution Protection Law (WPPL) in 1984, and the Air Pollution Protection Law (APPL) in 1987. With the laws as a legal basis, and with specific features having emerged from a bureaucratic developmental process, a set of ambient environmental standards were established during the 1980s. Consequently, a combination of 
the Pollutant Emission Permit Approach and the Sewage Charge System was introduced by SEPA in 1989. Since then, the industrial factories have had to register and apply for the emission permits from local municipalities before discharging.

Coupling of streams and the crucial decision. An event sequence graph of phase 1 is shown in Figure 3. In this phase, the Guanting water pollution first coupled with the 1st NEPC in the politics stream in 1973. However, this confluence was coupled with the policy stream after 15 years to create the window of opportunity for the emergence of the target policy. During those 15 years, only incremental steps took place in bureaucratic and legislative developments, accumulating strength to arouse radical change. In the politics stream, it is clear to see that the political strength was accumulated by power redistribution: The Communist Party of China (CPC) and the central government convened Plenary Session and NEPC respectively to raise the bureaucratic rank of the initial taskforce EPLG, signaling the importance of environmental protection. In the policy stream, several national environmental protection laws were gradually enacted and based on these laws the permit approach and the emission charging method were introduced by SEPA. There was, thus, another coupling of the politics and policy streams in 1989, which opened the first window for the emergence of the very initial environmental targets in China.

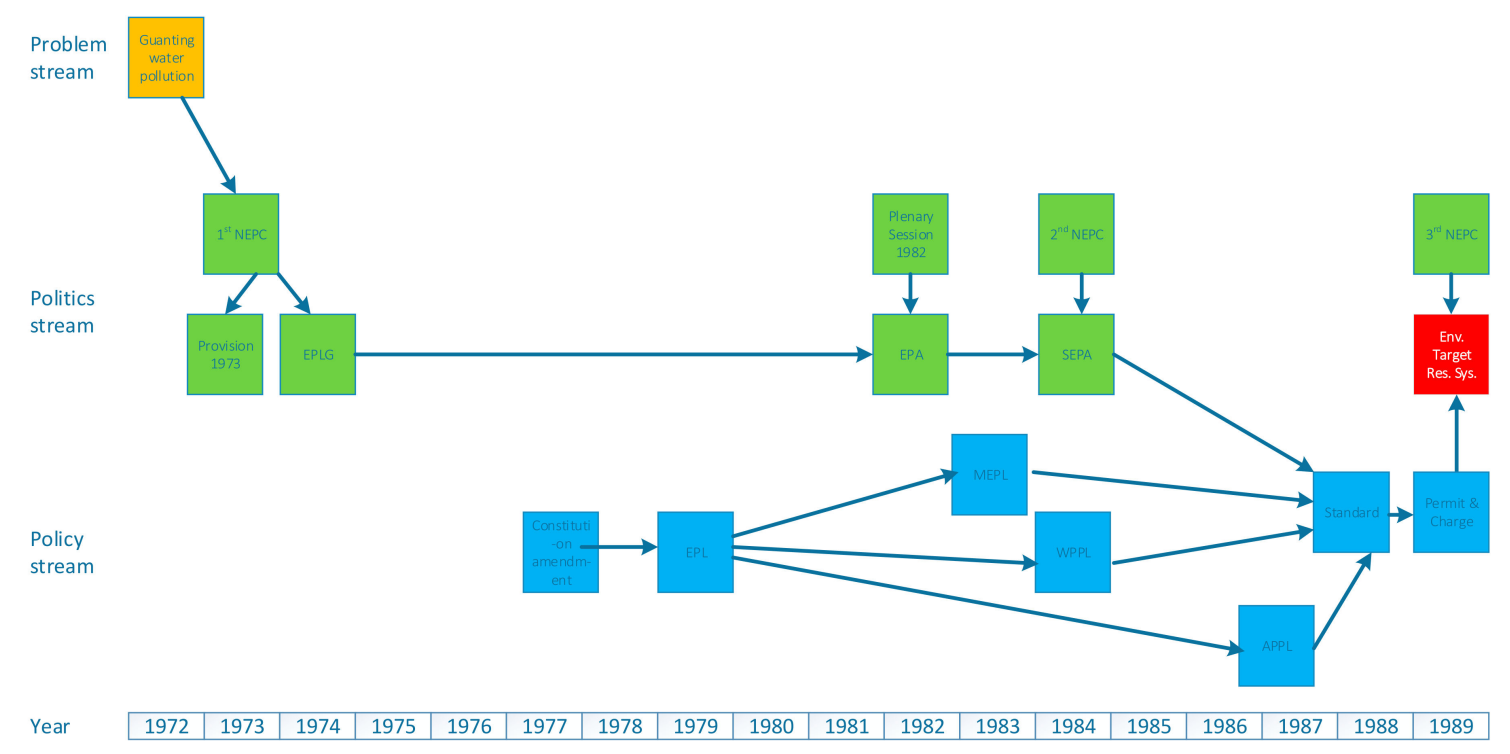

Figure 3. An event sequence graph of phase 1.

\subsection{Phase 2: Environmental Targets Banded with Cadre Evaluation, 1990-2002}

Problem stream. Since the environmental targets were banded with local municipalities that promoted economic performance, and there were no specific persons in charge of the targets. The local municipalities strategically set low targets and issued emission permits as long as the industrial enterprises applied for them. Consequently, during 1990-2002, the annual amount of wastewater discharge was increased by $26 \%$ from 35 billion tons to 44 billion tons, and the sulfur dioxide emissions were increased from 1498 billion tons to 1927 billion tons [18,19]. Apart from the emission indicators, two serious water pollution incidents happened in Guizhou and Yunnan provinces, causing a large number of fish die and drinking water crises.

Politics stream. Politics stream in this phase focused on building the cadre evaluation system. In 1994, the Fourth Plenary Session of the 14th CPC Central Committee was convened in Beijing and proposed that the leading cadres (i.e., the elected officeholders in Western literature) in government organizations should be comprehensively evaluated by a well-designed system of performance indicators. The Ministry of Organizations (MO) in China, in charge of cadre appointment, rotation, 
and promotion, perceived the spirits of the Plenary Session and formulated the Performance Evaluation Standards for Party and Government Leading Cadres in 1995. Seizing this opportunity, in the 4th NEPC in 1996, the central government again upgraded SEPA into State General Environmental Protection Administration (SGEPA) whose bureaucratic status was increased to the ministry level and, thus, local Environmental Protection Bureaus (EPBs) are correspondingly increased with bureaucratic rank and authority in environmental protection and enforcement. By doing so, the central government was determined to make the directors of local EPBs take the responsibility for environmental targets. Since then, the targets were peeled off from local municipalities, and banded with the leading cadres of local EPBs. Later in 2002, the central government reaffirmed this decision by launching the Selection and Appointment of Leading Cadres in the Environmental Protection System, which stipulates that the achievement of environmental targets is an important precondition for cadre promotion.

Policy Stream. Aside from the existing emission permit and charging policy, two major solutions have been proposed for safeguarding environmental targets. One is the Interim Measures for Environmental Statistics, which was jointly made by the SGEPA and the National Bureau of Statistics (NBS), and aimed to systematically record information on environmental indicators that was used to quantitatively calculate the cadres' performance on the achievement of environmental targets. Another is the National Five-Year Plan for Total Pollutant Discharge Control, which was released jointly by the SGEPA, the National Development and Reform Commission (NDRC), the Ministry of Commerce (MC), and the Ministry of Finance (MF). The aim of the Plan was to tackle the problem of local EPBs to strategically set low environmental targets, through formulating the ceiling of total pollutants that can be discharged in every five years in the local areas.

Coupling of streams and the crucial decision. An event sequence graph of phase 2 is shown in Figure 4. In this phase, the first coupling occurred between the politics and the policy streams in 1996. When SEPA was administratively raised to SGEPA, it had much stronger power of discourse to initiate cooperation with other ministries and commissions to jointly produce environmental policies. These policies, after about five years, coincided with the new development of cadre evaluation in politics stream and the compelling problem of increasing emissions to generate the window of opportunity for a new punctuation of linking environmental targets to cadre evaluation. One interesting point in this policy window was that the policy entrepreneurs involved several other ministries, commission and bureau that for themselves were not responsible for environmental protection. The SGEPA was able to call for cooperation from its peers to make joint solutions, because after its upgrade in bureaucratic rank it had equal right of discourse as the ministries. Before, the ministries would not give support to SEPA, in part because they were not at the same administrative level and, thus, SEPA as a "tiny" institution could not initiate dialogues with or mobilize resources from the ministries. 


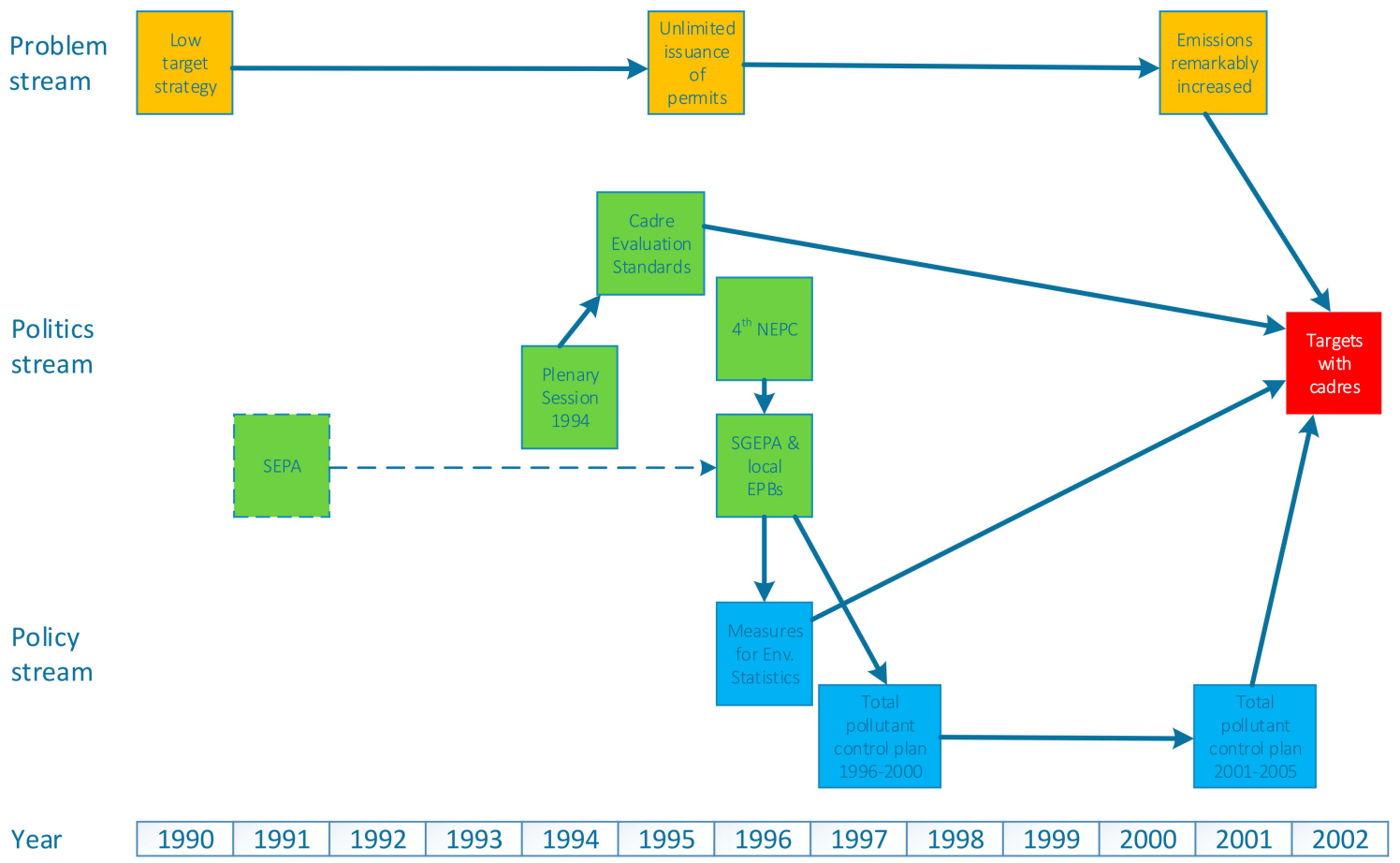

Figure 4. An event sequence graph of phase 2.

\subsection{Phase 3: Environmental Targets Banded with Economic Performance, 2003-2010}

Problem stream. During 2003-2010, the indicators have shown that the annual amount of wastewater discharge was increased from 46 billion tons to 69 billion tons in this period, and the sulfur dioxide emissions were increased from 1927 billion tons to 2589 billion tons [20]. Meanwhile, pollution crisis events occurred at an exponentially increasing speed. 28 large scale and severe water pollution events occurred across the country. These environmental problems were accompanied by managerial problems in the environmental sector. On the one hand, the local EPBs and the municipal governments had conflicting goals in terms of balancing environmental legitimacy and economic efficiency. Municipal governments, in pursuit of economic performance, may tolerate, or even encourage, entrepreneurial behavior that generated pollution. The local EPBs, which politically and administratively ranked lower than municipal governments, were left with little oversight power over polluting enterprises [21]. The SGEPA in Beijing, moreover, had inadequate human and technical capacities in supervising millions of industrial enterprises spread out all over the country. On the other hand, the environmental data have been manipulated by the local governments. At the municipal level, the statistical data on performance indicators were aggregated from multiple statistics bureaus in counties that collected data from the corresponding environmental authorities. When the data was unsatisfactory in terms of target achievement, the municipal government and its statistics bureau made an alliance to determine a method of handling this [22]. Actually, the local statistics bureaus faced substantial pressure when the performance data was unsatisfactory for the municipal leaders. The statistics people faced the dilemma of a dual role: on the one hand, they were constrained by the National Statistical Law that requires them to ensure the authenticity of the data and, on the other hand, they were under the administrative control of the municipal leaders who expected good numbers on both economic and environmental performance.

Politics stream. Kingdon argues that changes in the political stream may arise from swings of national mood, vagaries of public opinion, changes of administration and election results [6]. During 2003-2010 most of these forces were manifest, combining to create a politics stream triggering government actions for environmental protection. Before 2003, although there were some 
developments on target responsibility of cadres, the political salience of environmental protection was low. Public concern about environmental pollution was also sporadic and limited. However, in this phase, after a large number of serious water pollution crises took place and people living in the pollution locations were collectively found to have intestinal cancer (children were checked out with blood lead levels exceeded), a strong national mood was aroused regarding health damage caused by environmental pollution. Responding to public discontent, Hu Jintao's government, which came into power in 2003, made a commitment to balance environmental sustainability and economic development. The key moment was the launch of the Scientific Development Theory in the Third Plenary Session of the 16th CPC Central Committee in late 2003. Early next year, the central government with the new administration of $\mathrm{Hu}$ Jintao convened the National Forum on Population, Resources and Environment (NFPRE), and proposed the Green National Economic Accounting Method that evaluates local economic performance after deducting its resource consumption and environmental losses. Clearly smelling the central political commitment to scientific development and environmental protection, the Ministry of Supervision (MS, with the legal power to issue punishments) and the SGEPA jointly introduced the Regulations on Punishment of Illegal Activities of Environmental Protection in 2005. The Regulations set up the punishment rules for those local leading cadres who provided protective umbrellas for the enterprises that illegally discharge excessive pollution. To strengthen the implementation of the Regulations, the central government again upgraded SGEPA to an administrative position with higher enforcement power and named it the Ministry of Environmental Protection in China (MEP) in 2008.

Policy stream. The policy stream in this phase centered on solutions for saving energy and environmental impact assessment (EIA), and the assessment on enterprises' environmental behavior in particular [23]. The National Development and Reform Commission (NDRC) played a central role in this phase because it formulated China's Medium and Long Term Special Plan for Energy Saving in 2004 and introduced China's Terminal Energy Efficiency Project in 2005. The NDRC was under substantial pressure to act and had struggled to make energy policy an environmental issue. Both actions were aimed at providing scientific methods for industrial sectors to save energy and reduce emissions. Resonating with the NDRC, the central government launched the Suggestions on Promoting Healthy Development of the Coal Industry in late 2005, and the Implementation Plan for Energy-Saving and Emission Reduction Statistics, Monitoring, and Evaluation in 2007, for the purpose of reinforcing the statutory environmental targets. Based on these policies, China passed the Renewable Energy Law in 2005, the Energy-Saving Law in late 2007, and the Circular Economy Law in 2008.

Coupling of streams and the crucial decision. An event sequence graph of phase 3 is shown in Figure 5. In this phase, we also recognize a pattern of first coupling of the problem and politics streams. The politics stream responded to the environmental problems caused by rapid economic growth and environmental data manipulation by calling for Green GDP and punishment for cadres' illegal environmental behavior. However, this coupling is not strong enough to immediately bring about a new update of the target policy. On the one hand, SGEPA had no power to impose punishments on local cadres if they protected polluting enterprises. On the other, the policies to safeguard economic vitality after deduction of environmental losses did not exist. With the new developments of energy-saving techniques within the policy stream during 2004-2007, this coupling was given new momentum to generate a new punctuation. The energy policies gained favor because they tended to offer solutions for energy efficiency and, thus, they might provide an opportunity to China not to sacrifice economic growth by using clean energies or improving energy efficiency. This wish drove the central government to respond actively to the NDRC's energy approaches, and also made the central government feel confident in launching the idea of green GDP and hooking the environmental targets to economic records. 


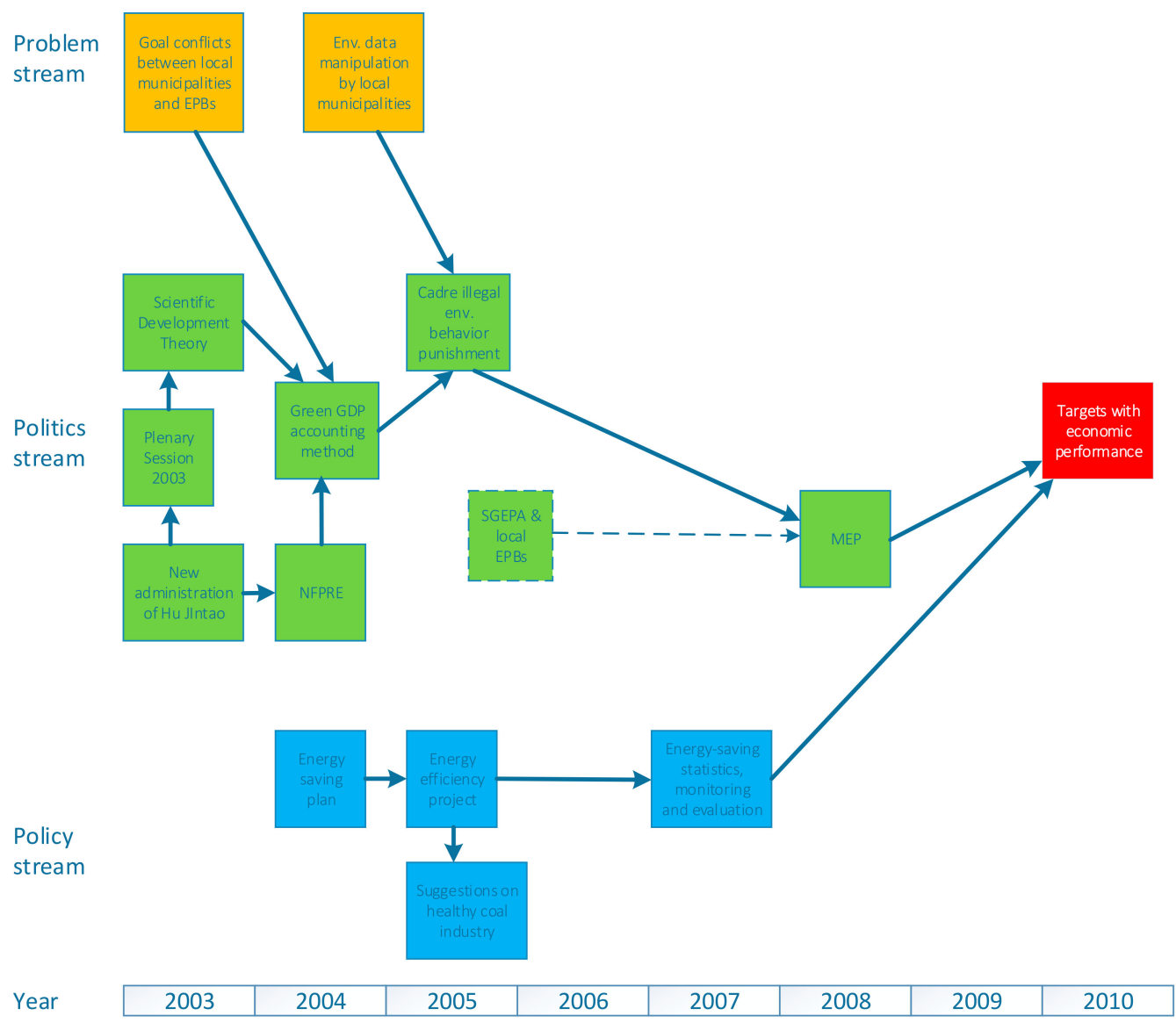

Figure 5. An event sequence graph of phase 3.

\subsection{Phase 4: Environmental Targets Banded with Central Fiscal Transfer Payment, 2011-2013}

Problem stream. During this relatively short period (2011-2013), 11 serious water pollution crises occurred in China, continuing to cause public discontent about environmental pollution and public health. Not limited to water pollution, China's air quality is also deteriorating. In the 2012 China Environment Bulletin released by the MEP, almost every city in China discharged excessive air pollutants [24]. In the 2013 report, it was shown that only three out of 74 cities that signed air quality responsibility contracts with the MEP met the targets; and 71 (95.9\%) cities were unable to fulfill their responsibility contracts. In addition, in December 2013, China experienced the most serious weather haze. Heavy haze started from Beijing in north China and extended to Shanghai in the south; and the haze weather lasted about 15 days. Beijing launched its "Defending the Blue Sky" program, but the city in 2013 had only reported about 100 days of "blue sky". Therefore, during 2011-2013, it became increasingly clear that the energy policies from the previous phase would not deliver radical emission reductions. Water pollution events continued to happen and the environmental problems extended from water to air.

Politics stream. In this phase, the key moment was the 7th NEPC in October 2011, during which the Opinions of the State Council on Strengthening the Key Work of Environmental Protection was launched. This showed the strong political commitment of the central government to environmental protection. The central idea of this document was to increase environment investments from the government side. The central government started to realize that the basic characteristic of China's fiscal semi-decentralization system has become an obstacle for local governments to invest in environmental protection. The central and local governments had a shared financial distribution structure since the 1994 Tax-Sharing System, in which the central government obtained the larger part of tax 
resources (the environmental tax and discharge fees in our case) and reallocated the money to balance regional economic and environmental protection among local governments. This has made the local governments unwilling to invest in environment protection or to levy tax on local polluting enterprises. The central government during this phase intended to seek solutions for this problem.

Policy stream. In prior Opinions by the central government in October 2011, the Ministry of Finance (MF) had earlier launched the Administrative Measures for Ecological Environmental Protection Pilot Projects in June 2011 and the Measures of Transfer Payment for National Key Eco-Industrial Areas in July 2011. These Measures broke the working mechanism of the tax-sharing system in China, and stipulated that the central money will go to the regions that have National Key Eco-Industrial Areas. That means, the central fiscal would never support poor environmental areas, but would be allocated to the areas that have good performance for environmental targets. In November 2011, the NDRC issued the Suggestions on Building the Ecological Compensation Mechanism for Eco-Industrial Parks, which further affirmed the approach proposed by MF.

Coupling of streams and the crucial decision. An event sequence graph of phase 4 is shown in Figure 6. In this phase, we see a first coupling between the politics and the policy streams. The principal policy entrepreneur was the Ministry of Finance, which did the most to couple the two streams by providing a reform in fiscal allocation and environmental subsidies usage. Although it did not identify the failure of the previous energy-saving policies, it formulated new measures before the central government was aware of the key fiscal issue prohibiting the local governments to environmental protection. However, this coupling did not bring about an immediate update on the target policy. It was not until the emergence of serious weather conditions in 2012 and 2013 that a formal policy punctuation was generated.

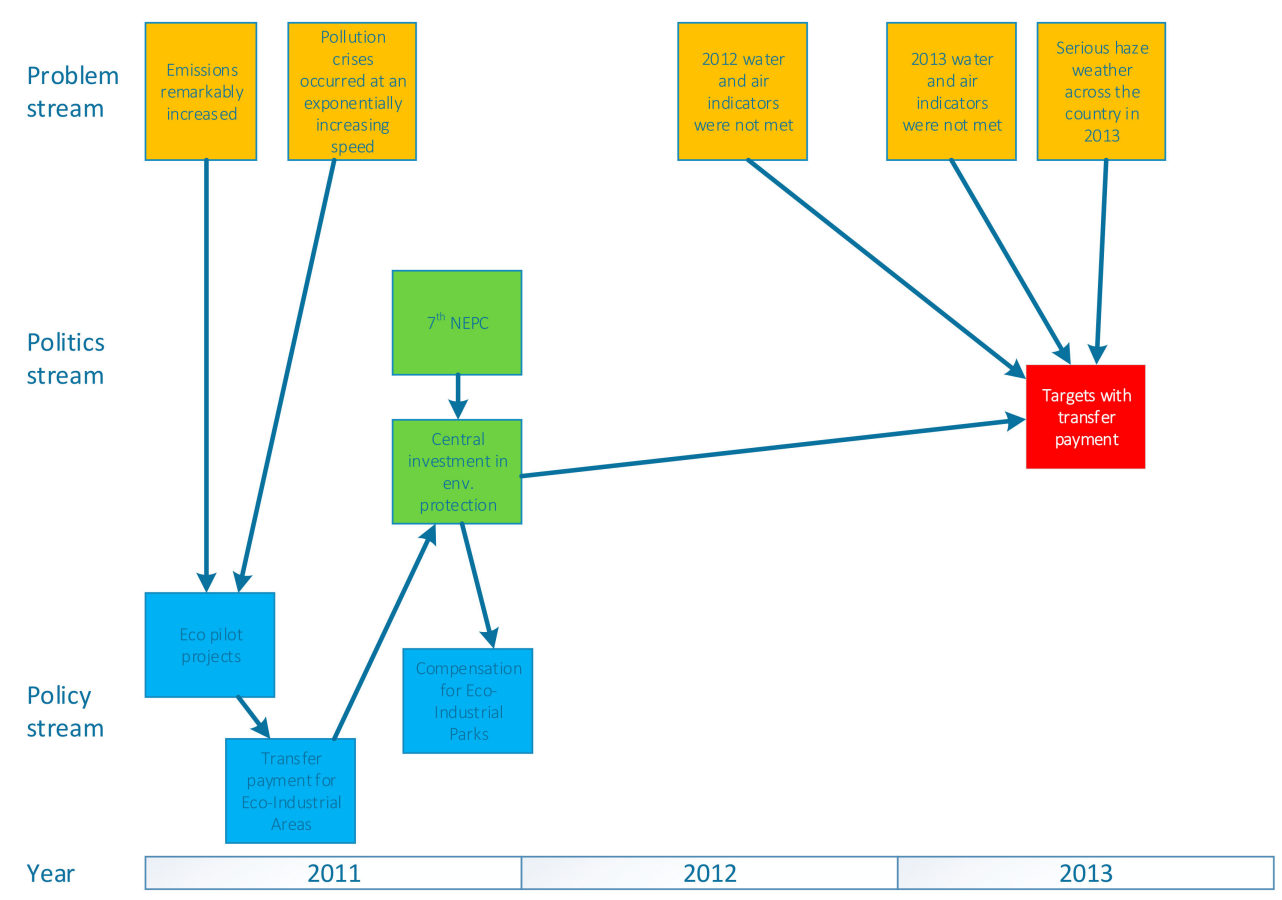

Figure 6. An event sequence graph of phase 4 .

\subsection{Phase 5: Environmental Targets Banded with Large Industrial Enterprises, After 2013}

Problem stream. The chief problem in this phase is the failure of the transfer payment policy in the previous phase. During 2013-2016, about 200 billion RMB had been allocated from the central fiscal to local eco-industrial areas [25]. However, such a large number of central fiscal transfer payments did not achieve their environmental objective. On the one hand, it has been reported by the National 
Audit Office (NAO) that in 2011 and 2012, 348 local authorities misappropriated the special funds on environmental protection [26]. On the other, the industrial enterprises in the national key eco-industrial areas are usually large state-owned enterprises; they are under direct control of the central government, and they have higher bureaucratic status than local authorities. As a result, these enterprises refused the local EPBs to monitor their environmental behavior [21]. Until 2016, 11 serious water pollution crises occurred in the eco-industrial parks. According to the annual environmental status reports by the MEP, China's air condition was also deteriorating. In 2014, 16 out of 161 cities that signed air contracts (9.9\%) accomplished the air targets, in 2015, 338 cities signed air contracts, and only 73 of them (21.6\%) met the air targets. In 2016 the proportion achieved 24.9\% [27-29]. In addition, heavy weather haze emerged more frequently, which even caused schools to close, and factories to shut down.

Politics stream. In 2013, Xi Jinping became the president of China and has given much of his commitment to market-based approaches instead of direct government subsidies of environmental protection, which led to the generation of environmental targets directly banded with the industrial enterprises. After one year of Xi Jinping in the central office, the Fourth Plenary Session of the 18th CPC Central Committee was convened. In the Plenary Session, more than 3000 local cadres were removed from their positions because of their illegal behavior of protecting polluting enterprises. Moreover, the Session highlighted that the construction of ecological civilization is the basic national policy, and that more efforts will be put into building beautiful China and realize the sustainable development of the country. More specifically, the Session brought about the idea of linking market instruments with environmental protection so that the enterprises with illegal environmental behavior can no longer survive in the market, and those environmentally-friendly enterprises will gain substantial supports from both government and market.

Policy stream. Encouraged by the new ideas in the politics stream, a combination of market-based instruments is brought forward by multiple actors in China. First, the MF and the State Administration of Tax (SAT) worked together on a number of "green tax" policies: the enterprises that sign environmental responsibility contracts with the MEP and accomplish the formulated environmental targets will enjoy a tax reduction on their revenue. Second, the Ministry of Commerce (MC) and the Ministry of Industry and Information Technology (MIIT) launched the "green government purchase" policy. The Chinese governments at all levels will only purchase products from those enterprises that are environmental friendly and achieve their environmental targets. Third, the MEP and the China Securities Regulatory Commission (CSRC) jointly published "green securities" policy. Only those enterprises that reach the environmental targets are able to apply for listing on the market and issue shares. Fourth, the MEP, the China Banking Regulatory Commission (CBRC) and the People's Bank of China (PBC) released "green credit" policies: the enterprises that have illegal environmental behavior records cannot obtain loans from any bank of China.

Coupling of streams and the crucial decision. An event sequence graph of phase 5 is shown in Figure 7 . In this phase, the three streams coupled together almost at the same time. The problems left over from the previous phase aroused the political attention of the new administration led by Xi Jinping. Market-based approaches were brought forward and provided the institutional context and opportunities within which specific "green" policies on environmental protection were created. The combination of green policies was brought forward by a diverse of actors. We recognize that the environmental policy actors in China are no longer limited within the environmental sector, and are extended to the industrial and financing sectors. The market constraints imposed on the enterprises, and the tax preferential policies together constituted the incentives of the enterprises to meet the environmental targets. Since, in this phase, China's environmental problem definition has been shifted from direct government control and oversight to enterprises' voluntary compliant behavior. 


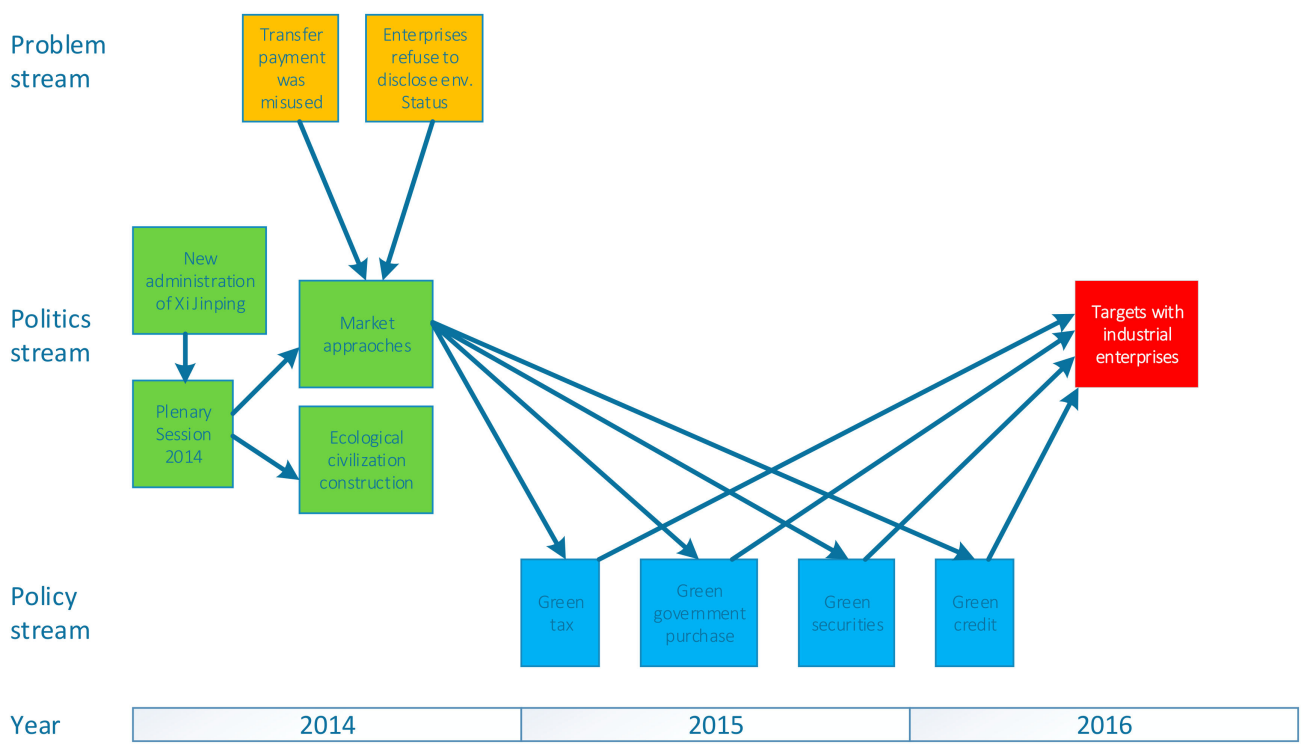

Figure 7. An event sequence graph of phase 5.

\section{Discussions}

From the above-mentioned empirical data, we find that the Chinese central government shows different bounded rationalities in different development phases of the ETP (Figure 8). In the first phase, the crucial decision is made by the central government when the political attention was attracted by water pollution crises, and there was a good fit between the problem of arbitrary discharge of polluting water and the solution of formulating discharge standards. In this phase, the rationality of the central government lies in the fact that it satisfies the solution of discharge standards to control water pollution. However, this rationality is bounded by the strategic behavior of the local governments. The local governments that have certain degrees of autonomy in setting standards establish low target levels in order to issue emission permits as many as possible.

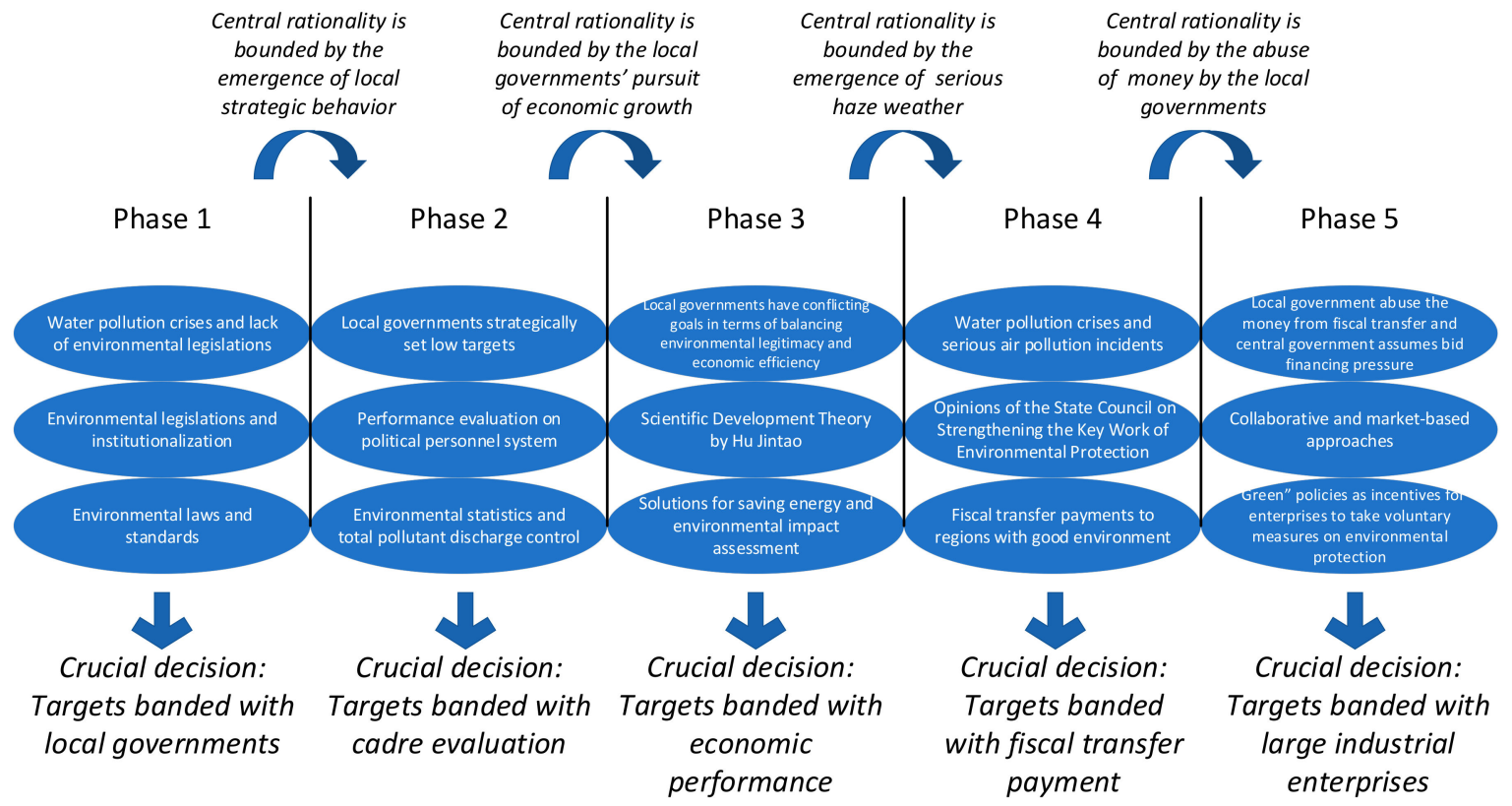

Figure 8. The succession of phases and the rationalities in the phases. 
This strategic behavior becomes the new problem of the central government in the implementation of ETP. Along with the political attention given to personnel evaluation by performance indicators, the development of environmental statistics and the introduction of total pollutant discharge control became feasible solutions for the creation of the new ETP. Therefore, in the second phase, the crucial decision is made to link environmental performance with political personnel evaluation. The local leading officials who achieve the environmental targets will obtain more promotion opportunities. In this phase, the rationality of the central government lies in introducing satisfactory solutions to prevent local strategic behavior. However, this rationality is bounded by local officials' conflicting goals in terms of balancing environmental legitimacy and economic efficiency.

As a result, in the third phase, the political attention of the central government shifted to the scientific development theory that emphasizes the deduction of environmental loss from economic achievement. To realize this, solutions regarding saving energy and environmental impact analysis were released; hereby, a crucial decision on the update of ETP was made. The rationality of the central government lies in providing local officials with feasible energy-saving techniques to balance economic growth and environmental sustainability. However, this economic rationality is bounded by the emergent air pollution incidents across the country.

Consequently, in the fourth phase, the central government gave strong political commitment to encourage air protection and air pollution control. The financial department enacted the fiscal transfer payment policy as the main solution. Consequently, the three streams became confluent and a crucial decision on the update of the ETP was made. In this phase, the rationality of the central government lies in providing fiscal incentives for local governments to be air friendly. However, this rationality is again bounded by the abuse behavior of local governments on the centrally-transferred money.

Given the new emergent problem of local abuse behavior, the political attention steered by the new president emphasized the use of market-based approaches and voluntary measures to the implementation of ETP. In this phase, the introduction on a set of green policies provided effective solutions and, thus, a new update of ETP emerged. In this phase, the rationality of the central government lies in the introduction of market-based approaches as satisfactory solutions for combatting local strategic behavior. Whether or not this rationality will be bounded depends on how strong and consistent the central attention is attached on the solutions.

\section{Conclusions}

The article aims to explore the question how the decisions on the ETP in different phases were made and how to explain the updates of the ETP in China. From the theoretical concept of bounded rationality and the empirical evidence, we conclude that the decisions on the ETP in different phases were made when policy windows were open with the coupling of the problem, politics, and policy streams. That said, the decisions on the ETP were made when two conditions were met: political attention was attracted by the problem and there was a good fit of policy solutions to the problem. During the coupling of the three streams, each decision was made under a specific rationality. As for the updates of ETP, we find that the rationalities of the central governments were limited by the emergent practices during ETP implementation, which gave momentum to the central government to seek new solutions and to revise and adapt the ETP.

The theoretical reflection of this article lies in the similarity and the difference of the meaning of bounded rationality in the Western context and in the Chinese context of decentralized authoritarianism. The similarity is that, in both contexts, the decision-makers are goal-oriented, and to achieve the goals the decision-makers do not search for and compare the entire solutions, but adopt a satisfactory solution. The decision-makers are able to learn from past experience and adapt their thoughts to the shape of the problem environment. Therefore, the Chinese decision-makers can be assumed to comply with the principles of intention and adaptation in bounded rationality [8]. However, the difference is that the rationality of the decision-makers in the Western context and in the Chinese context is bounded by different factors. That said, decision-makers face different types of uncertainties. Western scholars 
commonly recognize the "technical" uncertainties of the problem that limit rationality, including the tractability of the problem, the time available to make the decision (i.e., the more time a decision-maker spends on a problem, the more likely his or her understanding of the problem will appropriate the actual task environment and the limitations of human cognition fades), the information available for problem diagnose, and the accessibility or availability of the solution $[1,7,8]$. The Chinese context featured by decentralized authoritarianism gives more "political" uncertainties of the problem that constitute to bounded rationality. The central-local relations of the Chinese governments make the central government less certain of the behavior patterns and responding strategies of local governments. Therefore, the rationality of a decision-maker does not depend solely on one's own cognitive limitations, or the technical aspects of the problem, but also depends on the gaming responses of the interrelated actors involved in the problem.

Further, our findings yield important insights as to the environmental governance process in China. For example, we uncovered the major problems and problem dynamics in China's environmental protection. Not only limited to the natural environmental pollution, there are serious managerial problems that inhabit effective implementation of the target policy. Strategic behaviors of local governments emerged and changed from setting low target and issuing an unlimited number of discharge permits, to manipulating statistics data, and to abusing eco-compensation funds. Political attentions of China towards environmental issues are also shifting from cadre evaluation to green GDP, and then from transfer payments to large individual industrial enterprises. The changes in political attention drove environmental policy evolution from total pollution control to energy efficiency, and then from eco-compensation to green, voluntary, and market approaches. The evolving relationship between the different streams captures the tensions in the coupling of solutions and problems over time. A growing number of actors outside the environmental sector itself are involved in environmental governance, and it also implies that the achievement of environmental targets in the future will increasingly depend on the quality of cooperation between the environmental agency and its peers.

Supplementary Materials: The following are available online at www.mdpi.com/2071-1050/10/1/199/s1, Table S1: Problem events, Table S2: Politics events, Table S3: Policy events, Table S4: Actor names.

Acknowledgments: This work was supported by the National Natural Science Foundation of China under grant numbers 71774022 and 71403036.

Conflicts of Interest: The authors declare no conflict of interest.

\section{References}

1. Simon, H.A. Rationality in political behavior. Polit. Psychol. 1995, 16, 45-61. [CrossRef]

2. Anderson, J. Public Policy Making; Praeger: New York, NY, USA, 1979.

3. Bryson, J.M.; Crosby, B.C. Leadership for the Common Good, Tackling Public Problems in a Shared-Power World; Jossey-Bass: San Francisco, CA, USA, 1992.

4. Teisman, G.R. Models for research into decision-making processes: On phases, streams and decision-making rounds. Public Adm. 2000, 78, 937-956. [CrossRef]

5. Mintzberg, H.D. The Nature of Managerial Work; Harper and Row: New York, NY, USA, 1973.

6. Kingdon, J.W. Agendas, Alternative and Public Policies, 2nd ed.; Harper Collins: New York, NY, USA, 1995.

7. Jones, B.D. Bounded rationality. Annu. Rev. Polit. Sci. 1999, 2, 297-321. [CrossRef]

8. Jones, B.D. Bounded rationality and political science: Lessons from public administration and public policy. J. Public Adm. Res. Theory 2003, 13, 395-412. [CrossRef]

9. Landry, P.F. Decentralized Authoritarian in China; Cambridge University Press: New York, NY, USA, 2008.

10. Zhu, X.; Zhang, Y. Political mobility and dynamic diffusion of innovation: The spread of municipal pro-business administrative reform in China. J. Public Adm. Res. Theory 2016, 26, 535-551. [CrossRef]

11. Sato, H. The advocacy coalition framework and the policy process analysis: The case of smoking control in Japan. Policy Stud. J. 1999, 27, 28-44. [CrossRef]

12. Koppenjan, J.; Klijn, E.-H. Managing Uncertainties in Networks; Routledge: London, UK, 2004. 
13. Abbott, A.; Tsay, A. Sequence analysis and optimal matching methods in sociology. Sociol. Methods Res. 2000, 29, 3-33. [CrossRef]

14. Abell, P. The Syntax of Social Life: The Theory and Methods of Comparative Narratives; Clarendon Press: Oxford, UK, 1987.

15. Poole, M.S.; van de Ven, A.H.; Dooley, K.; Holmes, M.E. Organizational Change and Innovation Processes: Theory and Methods for Research; Oxford University Press: New York, NY, USA, 2000.

16. Wang, J. Water quality in Guanting reservoir. Water Air Soil Pollut. 1986, 29, 149-154.

17. Lotspeich, R.; Chen, A. Environmental protection in the People's Republic of China. J. Contemp. China 2007, 6, 33-59. [CrossRef]

18. State Environmental Protection Administration (SEPA). China Environment Bulletin 1990; State Environmental Protection Administration: Beijing, China, 1990.

19. State General Environmental Protection Administration (SGEPA). China Environment Bulletin 2002; State General Environmental Protection Administration: Beijing, China, 2002.

20. The Ministry of Environmental Protection (MEP). China Environment Bulletin 2010; The Ministry of Environmental Protection: Beijing, China, 2010.

21. Liu, N.N.; Wang, W.; Lo, C.; Zhan, X. Campaign-style enforcement and regulatory compliance. Public Adm. Rev. 2014, 75, 85-95. [CrossRef]

22. Li, J. The paradox of performance regimes: Strategic responses to target regimes in Chinese local government. Public Adm. 2015, 93, 1152-1167. [CrossRef]

23. Guo, X.; Marinova, D.; Hong, J. China's shifting policies towards sustainability: A low-carbon economy and environmental protection. J. Contemp. China 2013, 22, 428-445. [CrossRef]

24. The Ministry of Environmental Protection (MEP). China Environment Bulletin 2012; The Ministry of Environmental Protection: Beijing, China, 2012.

25. The Ministry of Finance (MF). Notice on Central Fiscal Transfer Payment to Local Key Eco-Industrial Areas in 2016; The Ministry of Finance: Beijing, China, 2016.

26. The National Audit Office (NAO). Audit Results on the Usage of Central Fiscal Transfer Payments in Energy Conservation, Renewable Energy and Comprehensive Utilization of Resources Projects; The National Audit Office: Beijing, China, 2013.

27. The Ministry of Environmental Protection (MEP). China Environment Bulletin 2014; The Ministry of Environmental Protection: Beijing, China, 2014.

28. The Ministry of Environmental Protection (MEP). China Environment Bulletin 2015; The Ministry of Environmental Protection: Beijing, China, 2015.

29. The Ministry of Environmental Protection (MEP). China Environment Bulletin 2016; The Ministry of Environmental Protection: Beijing, China, 2016. 